\title{
The Handle of the Broom
}

Alison Glover was one of the first to document significant practice variation in clinical care in a study on the incidence of tonsillectomy in school-age children in the United Kingdom in $1938 .{ }^{1}$ Since that time, there have been a number of studies linking clinical care practice variation with higher costs of care, ${ }^{2,3}$ and in many cases, these studies show that greater health-care expenditures do not necessarily lead to better outcomes or patient satisfaction. ${ }^{4,5}$ More recently, a number of studies have documented significant practice variation in clinical care in the pediatric ICU (PICU) setting. ${ }^{6-10}$ Reducing practice variation through standard care protocols and clinical pathways has been shown to reduce the costs associated with care, shorten the duration of mechanical ventilation, and reduce the stay in the PICU in a number of studies reported in this journal. ${ }^{11,12}$

In this issue of Respiratory CARE, Lowe et al ${ }^{13}$ report the findings of a retrospective analysis of a quality improvement intervention in their PICU whose primary aim was to standardize the use of $\beta$-agonists and airway clearance for critically ill children with acute respiratory failure. ${ }^{13}$ Physician-directed orders (pre-intervention group) were replaced by a standardized, respiratory therapistdriven protocol (post-intervention group). There were no significant differences in any of the demographics or severity of illness between the pre-intervention $(n=152$ subjects) and post-intervention ( $n=171$ subjects) groups. Even after controlling for age, sex, and severity of illness, there was a significant reduction in the number of $\beta$-agonist treatments, number of airway clearance interventions, duration of mechanical ventilation, and length of stay in the respiratory therapist-driven protocol group. Although the study did not assess the impact of the intervention on costs of care, it is certainly realistic to believe that reducing the number of $\beta$-agonist treatments by $37 \%$, the number of airway clearance interventions by $21.8 \%$, and the duration of mechanical ventilation by $25.2 \%$ would lower costs. Moreover, in a concomitant survey, the PICU staff felt that implementation of the therapist-driven protocol provided

Dr Wheeler has disclosed no conflicts of interest.

Correspondence: Derek S Wheeler MD MMM MBA, Cincinnati Children's Hospital Medical Center, 3333 Burnet Avenue, Cincinnati, OH 45229-3039. E-mail: Derek.Wheeler@cchmc.org.

DOI: $10.4187 /$ respcare. 05458 greater consistency of care as well as more effective and more efficient care. Finally, as has previously been shown, ${ }^{14}$ the PICU staff felt that implementation of the protocol elevated the status of the respiratory therapy staff and increased their perceived value as members of the PICU team.

See the Original Study on Page 259

Despite the evidence that supports minimizing practice variation, practitioners seem resistant to doing so; a common refrain is that standardization of care leads to "cookbook medicine" or that standardization of care impedes the ability to innovate. ${ }^{15}$ However, there is a way for PICU teams to be creative, innovative, and cutting-edge while being disciplined, regimented, and systematic at the same time. Rather than an "either/or" discussion ("you are either innovative or you are not"), standardization of care practices is very much a "both/and" discussion. Lillrank and Liukko ${ }^{16}$ classify processes into standards, routines, and non-routines. Standards are the processes where there is clearly a preferred way to do something, a best practice supported by solid evidence. These processes are usually repetitive in nature and are directly linked to specific outcomes. Deviation from the standard will result in worse outcomes. Non-routine processes are usually uncommon, highly variable, and specific to the clinical scenario. These kinds of processes lend themselves to a trial-and-error approach that encourages "out of the box" thinking. With these kinds of processes, there is room for flexibility and creative thinking. Between standards and non-routines are the routine processes in which there are usually one or 2 common approaches that will work. Lillrank and Liukko ${ }^{16}$ use a broom metaphor to describe these processes and how they should be managed. The rigid broomstick handle represents the standard processes, whereas the flexible bristles of the broom represent the non-routine processes. The routine processes lie somewhere in the middle. Using the broom metaphor, and based upon the results of the study by Lowe and colleagues, ${ }^{13} \beta$-agonist and airway clearance treatments are clearly standards (ie, the handle of the broom).

Derek S Wheeler MD MMM MBA Cincinnati Children's Hospital Medical Center University of Cincinnati College of Medicine

Cincinnati, Ohio 


\section{EDITORIALS}

\section{REFERENCES}

1. Glover JA. The incidence of tonsillectomy in school children. Proc R Soc Med 1938;31(10):1219-1236.

2. Fisher ES, Wennberg DE, Stukel TA, Gottlieb DJ, Lucas FL, Pinder EL. The implications of regional variations in Medicare spending. Part 1: The content, quality, and accessibility of care. Ann Intern Med 2003;138(4):273-287.

3. Fisher ES, Wennberg JE. Health care quality, geographic variations, and the challenge of supply-sensitive care. Perspect Biol Med 2003; 46(1):69-79.

4. Fisher ES, Wennberg DE, Stukel TA, Gottlieb DJ, Lucas FL, Pinder EL. The implications of regional variations in Medicare spending. Part 2: Health outcomes and satisfaction with care. Ann Intern Med 2003;138(4):288-298.

5. Sirovich BE, Gottlieb DJ, Welch HG, Fisher ES. Regional variations in health care intensity and physician perceptions of quality of care. Ann Intern Med 2006;144(9):641-649.

6. Straney L, Clements A, Alexander J, Slater A, ANZICS Paediatric Study Group. Variation in duration of respiratory support among Australian and New Zealand pediatric intensive care units. Pediatr Crit Care Med 2011;12(1):9-13.

7. Bratton SL, Newth CJ, Zuppa AF, Moler FW, Meert KL, Berg RA, et al. Critical care for pediatric asthma: wide care variability and challenges for study. Pediatr Crit Care Med 2012;13(4):407-414.
8. Pierce HC, Mansbach JM, Fisher ES, Macias CG, Pate BM, Piedra $\mathrm{PA}$, et al. Variability of intensive care management for children with bronchiolitis. Hosp Pediatr 2015;5(4):175-184.

9. Gupta P, Tang X, Gossett JM, Gall CM, Lauer C, Rice TB, Wetzel RC. Variation of ventilation practices with center volume after pediatric heart surgery. Clin Cardiol 2015;38(3):178-184.

10. Carroll CL, Faustino EV, Pinto MG, Sala KA, Canarie MF, Li S, et al. A regional cohort study of the treatment of critically ill children with bronchiolitis. J Asthma 2016;53(10):1006-1011.

11. Maselli DJ, Fernandez JF. Can respiratory therapist-driven protocols improve resource utilization? Respir Care 2013;58(3):546-547.

12. Modrykamien AM, Stoller JK. The scientific basis for protocoldirected respiratory care. Respir Care 2013;58(10):1662-1668.

13. Lowe GR, Willis JR, Bai S, Heulitt MJ. Implementation of a $\beta$ Agonist/Airway Clearance Protocol in a Pediatric ICU. Respir Care 2017;62(3):259-267.

14. Metcalf AY, Stoller JK, Habermann M, Fry TD. Respiratory therapist job perceptions: the impact of protocol use. Respir Care 2015; 60(11): 1556-1569.

15. Stoller JK. Implementing change in respiratory care. Respir Care 2010;55(6):749-757.

16. Lillrank P, Liukko M. Standard, routine, and non-routine processes in health care. Int J Health Care Qual Assur Inc Leadersh Health Serv 2004;17(1):39-46. 